\title{
Correction to: Killing spinor-valued forms and their integrability conditions
}

\author{
Petr Somberg $^{1}$ (D) $\cdot$ Petr $\operatorname{Zima}^{1}$ (D)
}

Accepted: 3 February 2021 / Published online: 10 March 2021

(c) Springer Nature B.V. 2021

\section{Correction to: Annals of Global Analysis and Geometry https://doi.org/10.1007/s10455-020-09730-9}

The funding needs to read as follows:

The authors gratefully acknowledge the support of the Grants GA19-06357S, GAUK 700217 and SVV-2017-260456.

The original article has been corrected.

The original article can be found online at https://doi.org/10.1007/s10455-020-09730-9.

Petr Zima

zima@karlin.mff.cuni.cz

Petr Somberg

somberg@karlin.mff.cuni.cz

1 Mathematical Institute of Charles University, Sokolovská 83, Praha 8, Karlín, Czech Republic 